\title{
A multidimensional environmental evaluation of packaging materials
}

\author{
Chien-Chung Huang*, Hwong-Wen Ma \\ Graduate Institute of Environmental Engineering, National Taiwan University, Taipei, Taiwan, ROC
}

Accepted 31 October 2003

\begin{abstract}
To reduce environmental damage, the properties of environmental issues must be understood. Most previous research has performed relevant assessment either qualitatively or quantitatively. This paper provides a new comprehensive evaluative framework to integrate these two types of approaches. Three methods are combined: (1) life cycle assessment (LCA), a quantitative method, to assess environmental loading, (2) analytic hierarchy process (AHP), a qualitative method, to obtain opinions from experts, and (3) cluster analysis to integrate the results of the former two methods. This new framework could provide integrated information and avoid a bias towards either qualitative or quantitative approach. To present the process of this new evaluative framework, packaging materials are selected as the case study in this paper.
\end{abstract}

(c) 2003 Elsevier B.V. All rights reserved.

Keywords: Life cycle assessment (LCA); Analytic hierarchy process (AHP); Cluster analysis; Packaging materials

\section{Introduction}

The main purpose of this paper is to implement qualitative and quantitative assessments simultaneously in considering complex environmental issues. Although quantitative approaches could present some characteristics in numerals and are often preferred, some considerations that are not easily quantified are apt to be neglected. To present the process of this new evaluative framework,

\footnotetext{
*Corresponding author. Present address: No.19, Lane 67, Sisian 1st St., West District, Tainan City 703, Taiwan, ROC. Tel.: + 886-6-250-95-90; fax: +886-6-250-53-56.

E-mail addresses: F87541201@ms87.ntu.edu.tw (C.-C. Huang), middle@ms21.url.com.tw (C.-C. Huang).
}

packaging materials of soft drinks are selected as a case study in this paper.

Packaging has a relatively short lifetime. Consequently, the amount of packaging waste approximately equals the amount of packaging on the market. In Europe, Packaging waste represents approximately $17 \%$ of municipal solid waste by weight and $3 \%$ of the total waste stream. Furthermore, Packaging waste represents a high proportion of the wastage of some specific materialsapproximately $70 \%$ for glass, $60 \%$ for plastics and $40 \%$ for paper and cardboard (European Commission, 2001).

In Europe, the amount of packaging consumed in 1998 was 58 million tonnes. An average of 155 $\mathrm{kg}$ of packaging materials was consumed per 
person in 1998. EU member states found that packaging waste was a serious problem in the 1980 s and introduced comprehensive legislation accordingly. In 1994, Directive 94/62/EC was adopted. This Directive aimed to harmonize national measures to reduce the impact of packaging and packaging waste on the environment. It contained provisions on the prevention of packaging waste, on the re-use of packaging and on the recovery and recycling of packaging waste. Member states were required to set minimum targets for packaging waste recovery and recycling.

In Taiwan, the Taiwan government announced the Resource Recycling and Reuse Act on 3 July, 2002 on packaging materials in to order reduce the increasing amount of wasted packaging materials.

No matter how waste packaging materials are treated, increasing the consumption of materials increases the environmental burden. Therefore, much research has addressed the environmental effects of packaging materials in the last decade. Many approaches have been used, such as questionnaire investigation, risk assessment, environmental impact assessment, environmental auditing, substance flow analysis, material flow analysis and LCA (Hertwich et al., 1997; Finnveden and Ekvall, 1998; Ayalon et al., 2000).

One type of approach used in these researches is quantitative, and tends to be more statistically based and makes much use of numerical data. In general, quantitative approach includes monetary methods (ex: cost and benefit analysis) and estimating the pollution emission and energy consumption (ex: material flow analysis and LCA). Ayalon et al. (2000) used monetary methods to derive the cost associated with environmental externalities of polyethylene terephthalate (PET), aluminum and glass bottles. Freire et al. (2001) analyzed the policies of bottled water in Portugal using a mathematical model that integrated monetary costs and environmental burdens. Kooijman (1993) compared different product/package combinations for peas in terms of mass flow, energy flow and air emission. Song and Hyun (1999) compared the various waste management scenarios for PET bottles using LCA methodology. Worrell et al. (1995) discussed the potential for improving the material efficiency of plastic packaging by measuring the cost-effectiveness. Kuta et al. (1995), tried to identify options to improve products and packaging using life cycle analysis.

The other type of approach is qualitative, and is a research method that relies less on numbers and statistics but more on interviews, observations, small numbers of questionnaires, focus groups, subjective reports and case studies. Some studies have used questionnaires to assess the perceived environmental friendliness of selected products and integrated three investigations of consumer conception of environmental friendliness of packaging (Van Dam and Van Trijp, 1994; Van Dam 1996). Oki and Sasaki (2000) indicated that some functions of the packaging materials, including the prevention of food contamination, protection against spoilage, preservation of contents and communication between the food manufacturer and the customer, are too complex to be expressed using quantitative methods. Thus, they constructed a qualitative evaluation framework to include environmental impact, cost and effect.

The two types of evaluation approaches consider different features. Bryman and Burgess (1999) pointed out that quantitative methods better establish cause-and-effect relationships, but qualitative methods address how subjects perceive the relationship between facets of their environment. Often the quantitative approach is preferred in decisionmaking. However, some considerations are not easily and correctly quantified. The qualitative information should be regarded as well as the quantitative aspects. This paper aims to establish a multidimensional environmental evaluation framework to combine quantitative and qualitative approaches. This investigation analyzes both the quantitative environmental burdens and qualitative opinions of experts. Accordingly, more complete information can be obtained to support decisionmaking on reducing the environmental burdens from packing materials.

\section{Methods}

Three methods were employed to derive the environmental effects of materials: (1) analytic hierarchy process (AHP), a qualitative method for 
obtaining the opinion of experts, (2) life cycle assessment (LCA), a quantitative method for assessing environmental loading, and (3) cluster analysis for integrating the results of the two previous methods.

In this research, life cycle assessment was used to quantify the potential environmental impact of a range of packaging materials by 'LCA point', which is estimated with SimaPro software and represents the consequence of all environmental loading in LCA. The higher numerals of 'LCA point' represent the more environmental burdens. However, as many characteristics of materials are not easily quantified, expert opinions were obtained using an AHP survey and an 'AHP score' of materials was derived. AHP scores are obtained through the weight of AHP multiply by the individual given score associated evaluation factor. The higher numerals of 'AHP score' represent the less environmental concerns. Finally, cluster analysis was applied to categorize specific materials into groups according to their characteristics. Fig. 1 presents a flowchart for this process.

To collect the data of packaging materials used in this research, we surveyed all the soft drinks on the market and selected nine popular packaging materials. They are polyethylene terephthalate (PET) containers, high density polyethylene (HDPE) containers, polypropylene (PP) containers, polystyrene (PP) containers, steel containers, aluminum containers, glass containers, cardboard boxes, and liquid paperboards (LPB, e.g. Tetra Paks). Among these, cardboard boxes and liquid paperboards are both complex materials that are principally made from paper. Cardboard boxes are $85 \%$ paper and $15 \%$ PE, but liquid paperboards are $73.5 \%$ paper, $21 \% \mathrm{PE}$ and $5.5 \%$ aluminum foil.

\subsection{Quantitative research: life cycle assessment $(L C A)$}

\subsubsection{The applications of $L C A$}

LCA has received much attention in the environmental field since 1990. The first attempt to look at extended product systems was as early as the 1960s (Curran, 1996). The area of packaging has been a major focus of the application of LCA

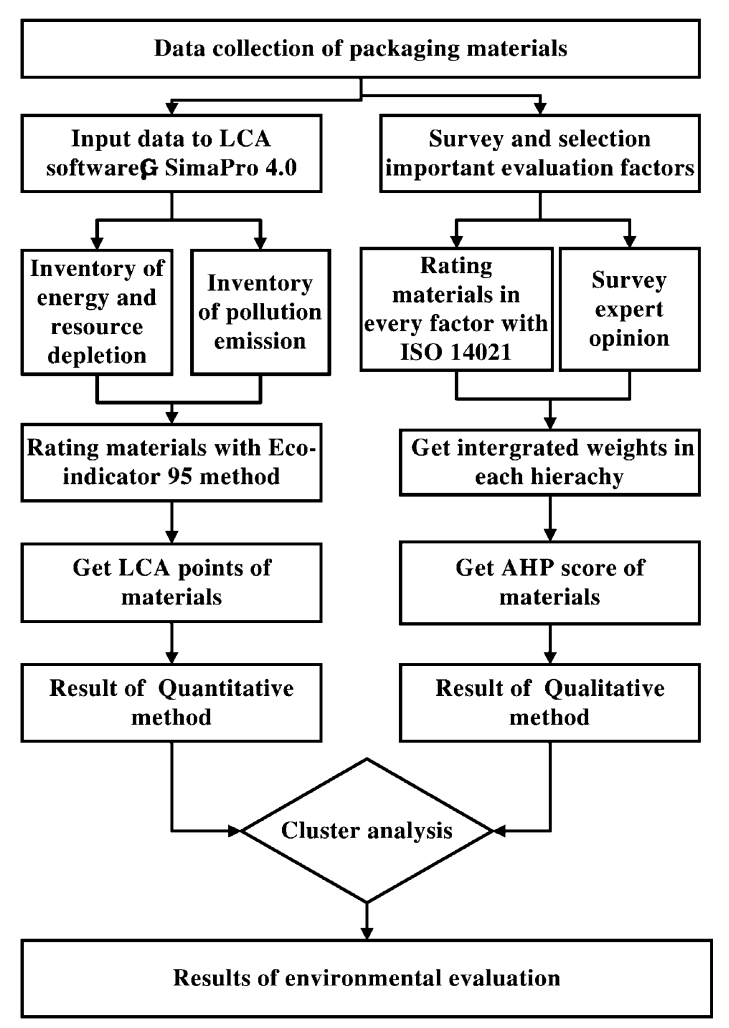

Fig. 1. Investigation process.

studies. By 1969, the Coca Cola Company had already quantified the material, energy and environmental consequences of packaging over its entire life cycle (Sonneveld, 2000). More than $40 \%$ of LCA studies published between 1970 and 1992 are estimated to be concerned with packaging materials (Knoepfel, 1994). All material requirements, energy consumed, emissions, waste and environmental impact associated with the provision of a product, process or service, are quantified. Through the efforts of the Society of Environmental Toxicology and Chemistry (SETAC) in 1990's, the LCA method was stipulated in the ISO 14040 series in 1997 (ISO, 1997) and became a powerful decision support tool for environmental management. According to ISO 14040, life cycle assessment includes four phases, (1) goal and scope definition: shall be clearly defined and consistent with the intended application (2) inventory analysis: involves data collection and calculation pro- 
cedures to quantify relevant inputs and outputs of a product system (3) impact assessment: is aimed at evaluating the significance of potential environmental impacts using the results of the life cycle inventory analysis and (4) interpretation of results: is the phase of LCA in which the findings from the inventory analysis and the impact assessment are combined together.

\subsubsection{Functional unit and system boundary}

This paper is concerned with packaging materials of soft drinks. An LCA study should clearly specify the functions of the system under study. The 'functional unit' measures the performance of the functional output of the product system. The main function of the packaging of soft drinks is to contain the product; marking contents and increasing visual appeal are less important. Therefore, ' $\mathrm{g} /$ l' (grams of packaging materials/per liter beverage) was selected as the 'function unit' in this case. The beverage densities are all assumed to be equal to $1 \mathrm{~g} / \mathrm{ml}$. Table 1 presents the average number of function units associated with various packaging materials. Notably, bottle tops are often not made from the same material with bottles. Hence, all the materials in each container are considered separately. In order to simplify the system properly and delimit the research boundary, the study considered four stages of a life cycle on packing materials (see Fig. 2): resource extraction, manufacture, usage, and waste disposal. In Taiwan, $63 \%$ of waste goes into landfill sites, and another

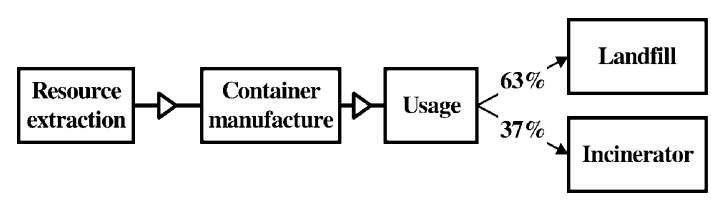

Fig. 2. The study boundary of LCA on packing materials.

$37 \%$ is incinerated (Taiwan EPA, 2002). The recycle stage was not included in this boundary. In fact, the recycled packaging materials will be reprocessed to other products, and will no longer be containers.

\subsubsection{Software and database}

SimaPro 4.0, which was designed according to the Eco-indicator 95 method by PRe Consultant, is the software used in this study. The Ecoindicator 95 is a model that represents the total environmental load of a process or material. It is computed using an LCA with a weighting step. The Eco-indicator 95 could compute 100 Ecoindicators for the most commonly used materials / processes (Goedkoop, 1995). The method considers nine environmental issues, which are ozone layer depletion, heavy metals, carcinogenic substances, summer smog, winter smog, pesticides, greenhouse effect, acidification and eutrophication. There are three kinds of database contained in the software. To suit the input data and consider the consistency, the BUWAL 250 database (developed

Table 1

Average function units of nine packaging materials

\begin{tabular}{llrl}
\hline $\begin{array}{l}\text { Packaging } \\
\text { materials/containers }\end{array}$ & $\begin{array}{l}\text { Average function units of } \\
\text { bottles }(\mathrm{g} / \mathrm{l})\end{array}$ & \multicolumn{1}{l}{$\begin{array}{l}\text { Average function units of } \\
\text { bottle tops }(\mathrm{g} / \mathrm{l})\end{array}$} \\
\hline PET containers & PET & 89.02 & PP \\
HDPE containers & HDPE & 59.57 & PP \\
PP containers & PP & 82.33 & PP \\
PS containers & PS & 57.00 & Aluminum foil \\
Steel cans & Tin plate & 156.27 & None \\
Aluminum cans & Aluminum ingots & 46.20 & None \\
Glass containers & Glass (brown) & 1015.63 & Aluminum ingots \\
Cardboard boxes & Cardboard liquid & 37.76 & PP \\
& PE & 6.66 & \\
Liquid paperboards & Cardboard liquid & 29.46 & None \\
& PE & 8.42 & \\
& Aluminum foil & 2.21 & 1.12 \\
\end{tabular}




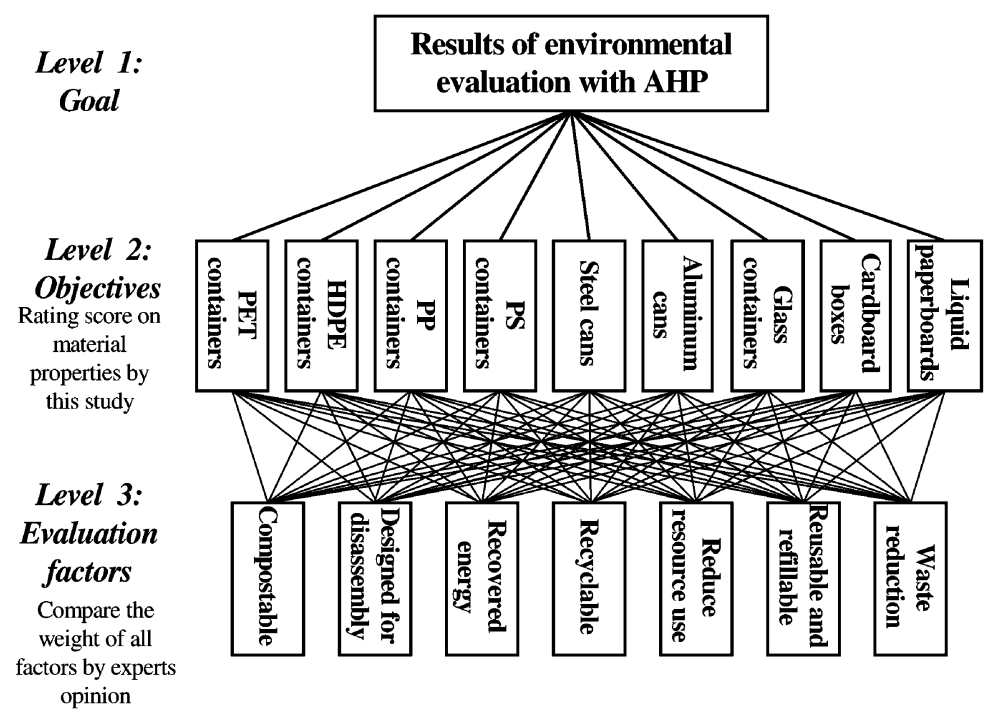

Fig. 3. The analytic hierarchy of AHP approach.

by Swiss Ministry of the Environment) and the IDEMAT 96 database (developed by Delft University of Technology in the Netherlands) are used. Under the circumstance that local Taiwan data is still unavailable, this study assumes the manufacture processes and inventory data of all containers are similar between Taiwan and Europe.

\subsection{Qualitative research: analytic hierarchy pro- cess $(A H P)$}

\subsubsection{Introduction of AHP}

Thomas L. Satty developed the analytic hierarchy process (AHP), a type of multiple-criteria decision-making process, in 1970s (Satty, 1980). This method reduces the uncertainties associated with multiple-criteria decision-making processes. AHP is developed to simplify complex problems systematically by constructing hierarchies. It involves a series of pairwise comparisons to determine the relative performance of each alternative (objective) in terms of each of the decision criteria.

\subsubsection{Selecting the evaluation factors}

Seven evaluation factors taken from ISO 14021 (ISO, 1999) are considered to assess environmental friendliness. They measure whether products are 'compostable', 'designed for disassembly', 'recyclable', 'reduce resource use', 'reusable and refillable', and whether they enable 'waste reduction' and 'recovery of energy'. After determining the objectives and evaluation factors, the analytic hierarchy of AHP approach was built as Fig. 3.

\subsubsection{The process of AHP}

The relative weights of evaluation factors were determined using AHP questionnaires. In AHP method, deviation from consistency may be represented by $\left(\lambda_{\max }-n\right) /(n-1)$ which we call the consistency index (C.I.). $\lambda_{\max }$ is the maximum eigenvalue and $n$ is the number of activities in the evaluation matrix. The ratio of C.I. to the average random index for the same order matrix is called the consistency ratio (C.R.). A consistency ratio of 0.10 or less is considered acceptable. The survey population consists of 72 professors of environmental science and engineering in Taiwan National Science Council's list. Forty-one samples were acceptable. Every material is weighted according to each evaluation factor, according to criteria ISO 14021. Appendix A lists the definitions of every evaluation factor, according to ISO 14021. Appendix B describes the weighting process. Every material is scored using associated evaluation factors. A total score is obtained by summing scores. 


\subsection{Cluster analysis}

Cluster analysis is a multivariate technique whose primary aim is to group objects according to their characteristics (Hair et al., 1995). Cluster analysis classifies objects such that each object is very similar to others in the same cluster, according to some predetermined selection criterion. The resulting clusters of objects should then exhibit high internal (within-cluster) homogeneity and high external (between-cluster) heterogeneity. Thus, if the classification is successful, the objects within clusters will be close together when plotted geometrically, and different clusters will be far apart.

The cluster variable determines the 'character' of the objects because it includes only the variables used to compare objects. In this study, the AHP score and the LCA point describe equally the character of each material.

The between-groups linkage method, which is a form of cluster analysis, was used to cluster results generated from AHP and LCA. The distance between two clusters is determined by averaging the distances between all pairs of subjects in the two clusters. The measured distance is the Squared Euclidean distance, as given by Eq. (1).

$D_{A B}=\sum_{j=1}^{p}\left(a_{j}-b_{j}\right)^{2}$

where $a_{j}$ and $b_{j}$ are the coordinates of $\mathrm{A}$ and $\mathrm{B}$ with reference to the $j$ th axis, representing the $j$ th dimension.

At first, AHP scores and LCA point must be standardized and expressed in the same unit (see Table 2).

The AHP score, SA, is standardized as,

$$
\mathrm{SA}=\frac{S_{i}-M s}{M s}
$$

where $S_{i}$ is the AHP score of material $i$, and $M s$ is the mean of all AHP scores.

The LCA score, SL, is standardized as,

$$
\mathrm{SL}=-\left(\frac{P_{i}-M p}{M p}\right)
$$

where $P_{i}$ is the LCA point of material $i$, and $M p$ is the mean of all LCA point.

The negative sign indicates less environmental impact. In the process of clustering, the materials can be divided into groups by the distance between them.

\section{Results and discussion}

In this case study, these two types of evaluation (qualitative and quantitative) do not yield very similar results. In LCA approach, because of emitting carcinogen and heavy metals, the Aluminum cans and glass containers are estimated less environmental friendly. But in AHP approach, cardboard boxes, liquid paperboards, and aluminum cans are inferior with regard to environmental issues, especially for their performance in the important factor 'Reduce resource use'. The followings are the results of these approaches.

\subsection{Results of LCA}

Fig. 4 shows the outcomes of the LCA and suggests that HDPE, PP containers and liquid paperboards incur less environment burden less than the other packaging containers. Aluminum cans and glass containers impact the environment more strongly when the whole life cycle is taken into account. This is because aluminum cans emit more carcinogen and glass containers emit more heavy metal in the manufacture stage in this model. But if only the waste disposal phase is considered, glass and PS containers have a worse environmental burden. However, the main environmental impact throughout the life cycle occurs during the manufacture phase (over 90\%). The evaluation shows that impact over the life cycle is primarily associated with the manufacture phase.

\subsection{Results of $A H P$}

In the responses to the questionnaire survey, 'compostable' and 'reduce resource use' are the most important factors; the factor weights are 0.25 and 0.20 , respectively. 'Designed for disassembly' and 'reusable and refillable' are less important 


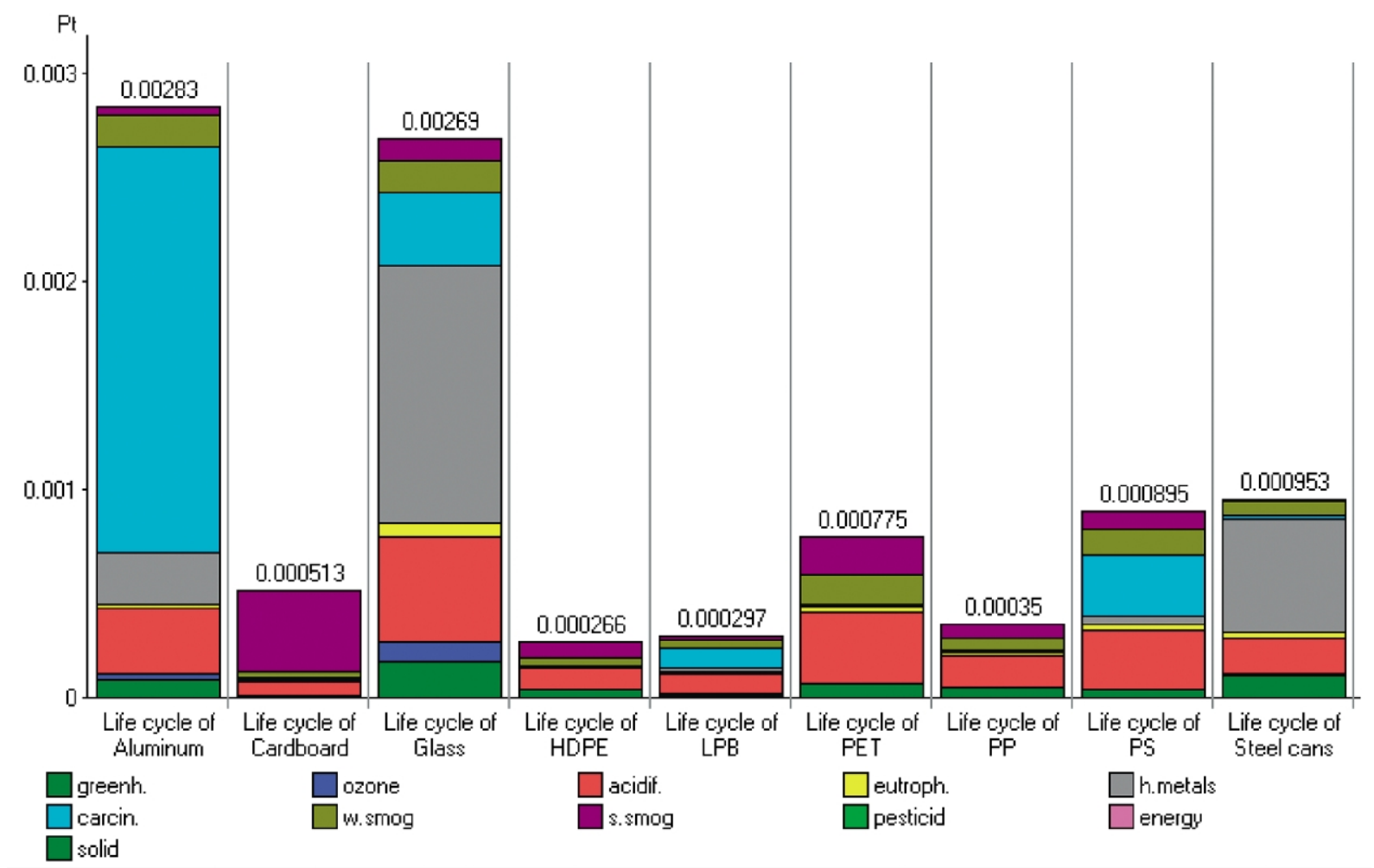

Compare boxes; Method: SimaPro 3.0 Eco-indicator 95/ Europe g / indicator

Fig. 4. LCA result of materials (all life cycle, unit: point, $\mathrm{Pt}$ ).

(0.10 and 0.05). Table 2 shows that PET, HDPE, PP containers are better and cardboard boxes, liquid paperboards, and aluminum cans are inferior, because PET, HDPE and PP containers were given higher scores in some high-weighted factors; such as 'reduce resource use' (the factor weight is 0.20 ) and 'recovered energy' (the factor weight is 0.13 ).

\subsection{Grouping with cluster analysis}

Fig. 5 geometrically illustrates the groups in the coordinate graph. The $x$-axis represents the standardized AHP score and the $y$-axis represents the standardized LCA point. HDPE, PP, PET and PS containers are all located in the first quadrant. It reflects that they have good performances in both LCA and AHP approaches. Liquid paperboards, cardboard boxes, and steel cans are all located in the second quadrant, indicating that they have good performance in LCA approach, but not in AHP approach. The same observation applies to the situation of aluminum cans and glass containers in the third quadrant. Their performances are worst in both LCA and AHP approaches.

In the view of numeric, the groups can be ranked according to environmental friendliness, as in Table 3. Overall, PET, PS, HDPE and PP containers seem preferred materials for the environment, according to this study. Glass bottles and aluminum cans have more impact. The groups are described in more detail to explain these results.

\subsubsection{Group 1}

The containers in this group are all plastics and have similar characteristics. The AHP method gives them all high scores in 'recovered energy' and 'reduced resource use', because they have high heat values in incinerators and use little 
energy in production. Results from the LCA revealed that HDPE and PP bottles also have little potential environmental impact. However, when the disposal phase is considered using the LCA method and the Sima Pro software, PS and PET containers yield more heavy metals to the environment by incinerating. However, PS and PET bottles perform moderately in terms of LCA because their environmental impact in the disposal phase is weaker. However, overall, PET, PS, HDPE and PP bottles are still the best materials.

\subsubsection{Group 2}

Cardboard boxes, liquid paperboards, and steel cans belong to this group. In fact, they are not bad in terms of LCA, but their AHP scores are lower. Finally, they perform moderately in terms of environmental damage. The reason of their lower AHP scores is their worse performance in some important factors, such as 'Recovered energy' and 'Reduce resource use'.

\subsubsection{Group 3}

Glass containers and aluminum cans, poor in terms of AHP, score lowest for 'Recovered energy', and 'Reduce resource use' for several reasons. First, these two materials release little heat in incinerators, and second, glass containers assume more amounts of materials and aluminum cans require much energy to refine the aluminum ingots. According to the BUWAL database, significant quantities of carcinogens and heavy metals ema-

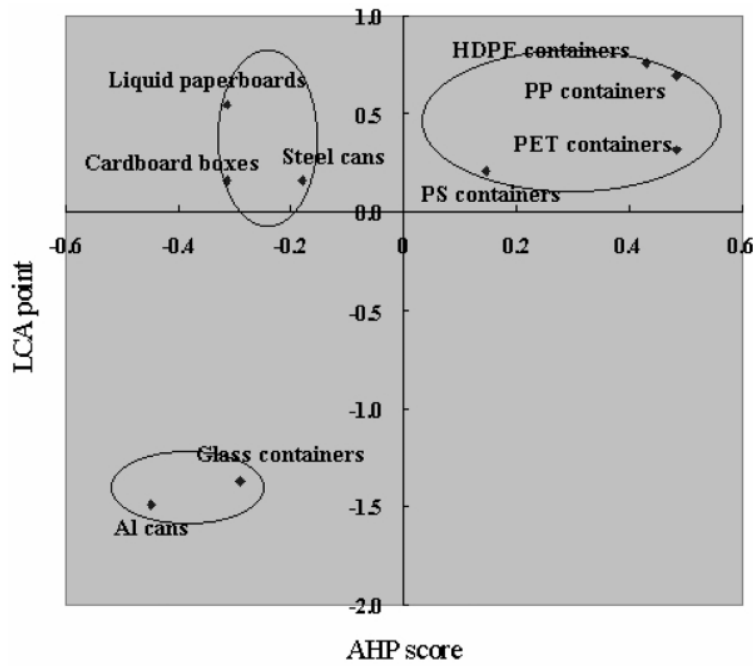

Fig. 5. Plot of LCA point and AHP score.

nate from aluminum cans and glass bottles, respectively. Carcinogens and heavy metals are significant environmental burdens. For the reasons already stated, glass containers and aluminum cans have worse performances not only in LCA but also AHP approach.

\section{Conclusion}

In assessing the environmental impact of various container materials, past studies have applied either

Table 2

Standardization of AHP score and LCA point

\begin{tabular}{|c|c|c|c|c|c|c|}
\hline Materials & $\begin{array}{l}\text { AHP } \\
\text { score }^{1}\end{array}$ & In order $^{2}$ & $\begin{array}{l}\text { LCA } \\
\text { point }^{3}\end{array}$ & In order $^{2}$ & $\begin{array}{l}\text { Standardization of } \\
\text { AHP score }\end{array}$ & $\begin{array}{l}\text { Standardization of } \\
\text { LCA point }\end{array}$ \\
\hline PET containers & 1.32 & 1 & $7.75 \mathrm{E}-04$ & 4 & 0.485 & 0.32 \\
\hline PP containers & 1.32 & 1 & $3.50 \mathrm{E}-04$ & 3 & 0.485 & 0.69 \\
\hline HDPE containers & 1.27 & 3 & $2.66 \mathrm{E}-04$ & 1 & 0.42875 & 0.77 \\
\hline PS containers & 1.02 & 4 & $8.95 \mathrm{E}-04$ & 6 & 0.1475 & 0.21 \\
\hline Steel cans & 0.73 & 5 & $9.53 \mathrm{E}-04$ & 7 & -0.17875 & 0.16 \\
\hline Glass containers & 0.63 & 6 & $2.69 \mathrm{E}-03$ & 8 & -0.29125 & -1.37 \\
\hline Cardboard boxes & 0.61 & 7 & $5.13 \mathrm{E}-04$ & 4 & -0.31375 & 0.55 \\
\hline Liquid paperboards & 0.61 & 7 & $9.53 \mathrm{E}-04$ & 2 & -0.31375 & 0.16 \\
\hline Aluminum cans & 0.49 & 9 & $2.83 \mathrm{E}-03$ & 9 & -0.44875 & -1.49 \\
\hline
\end{tabular}

Higher scores have less environmental impact.

In environmental friendly order.

Higher points have more environmental impact. 
Table 3

The result of grouping with cluster analysis

\begin{tabular}{ccc}
\hline Grouping Result & Packaging Materials \\
\hline Group 1 & PET containers \\
& PS containers \\
& HDPE containers \\
& PP containers \\
Cardboard boxes & More Environmental Friendly \\
Liquid paperboards & Steel cans \\
& Glass containers & Less Environmental Friendly \\
\hline
\end{tabular}

qualitative or quantitative methods and have not addressed all phases of life cycle and have only selected one or few materials. To obtain comprehensive evaluation of all container-packaging materials used frequently on the market, this study selects nine kinds of container and develops a new evaluation framework that incorporates multidimensional considerations to support decisionmaking. Not all the attributes of a material are easily quantified. Qualitative information should be regarded and considered as well as quantitative information. By cluster analysis approach, a multivariated data analysis technology, the qualitative AHP method and the quantitative LCA method were combined to evaluate the environmental impact of packaging materials.

To show and compare the consequences of AHP and LCA approaches, ordinal list is generally used. But in fact, the distances between every two results are different. For example, in the ordinal list of AHP scores (see Table 2), PS containers, steel cans, glass containers are shown as the forth, fifth and sixth. But the distance between PS containers and steel cans is longer than that between Steel cans and Glass containers. Therefore, the adjacent positions in the ordinal list may have different properties when the results are compared. By means of cluster analysis, the shortcoming could be overcome. Cluster analysis could arrange the evaluation results into several groups properly. Then, we could explain the materials in view of groups, instead of in individuals, and also could synthesize the results of these two approaches.

Since the paper focuses on the development of the integration framework, the case study makes assumptions in the use of database, which is the major limitation of this case study. In order to have more realistic results, the local database should be established.

\section{Acknowledgments}

The authors would like to thank the National Science Council of the Republic of China for financially supporting this research under Contract No. NSC 89-2621-Z-002-073. 


\section{Appendix A: Definition of evaluation factors in ISO 14021}

Evaluation factors

Compostable

Designed for disassembly

Recovered energy

Recyclable

Reduce resource use

Reusable and refillable

Waste reduction
ISO14021 definition

A characteristic of a product, packaging or associated component that allows it to biodegrade, generating a relatively homogeneous and stable humus-like substance.

A characteristic of a product's design that enables the product to be taken apart at the end of its useful life in such a way that allows components and parts to be reused, recycled, recovered for energy or, in some other way, diverted from the waste stream.

A characteristic of a product that has been made using energy recovered from material or energy that would have been disposed of as waste but instead has been collected through managed processes. A characteristic of a product, packaging or associated component that can be diverted from the waste steam through available processes and programmes and can be collected, processed and returned to use in the form of raw materials or products.

A reduction in the amount of material, energy or water used to produce or distribute a product or packaging or specified associated component.

Reusable:

A characteristic of a product or packaging that has been conceived and designed to accomplish within its life cycle a certain number of trips, rotations or uses for the same purpose for which it was conceived.

Refillable:

A characteristic of a product or packaging that can be filled with the same or similar product more than once, in its original form and without additional processing except for specified requirements such as cleaning or washing.

Reduction in the quantity (mass) of material entering the waste stream as a result of a change in the product, process or packaging.

\section{Appendix B: Weighting process of AHP method}

\begin{tabular}{|c|c|c|c|c|c|c|c|c|c|c|}
\hline $\begin{array}{l}\text { Evaluation } \\
\text { factors }\end{array}$ & $\begin{array}{l}\text { Weight } \\
\text { of AHP }\end{array}$ & $\begin{array}{l}\text { PET } \\
\text { bottles }\end{array}$ & $\begin{array}{l}\text { HDPE } \\
\text { bottles }\end{array}$ & $\begin{array}{l}\text { PP } \\
\text { bottles }\end{array}$ & $\begin{array}{l}\text { PS } \\
\text { bottles }\end{array}$ & $\begin{array}{l}\text { Steel } \\
\text { cans }\end{array}$ & $\begin{array}{l}\text { Aluminum } \\
\text { cans }\end{array}$ & $\begin{array}{l}\text { Glass } \\
\text { bottles }\end{array}$ & $\begin{array}{l}\text { Cardboard } \\
\text { boxes }\end{array}$ & LPB \\
\hline Compostable $^{1}$ & 0.23 & 0 & 0 & 0 & 0 & 0 & 0 & 0 & 1 & 1 \\
\hline $\begin{array}{l}\text { Designed for } \\
\text { disassembly }^{2}\end{array}$ & 0.10 & 1 & 1 & 2 & 1 & 2 & 2 & 2 & 0 & 0 \\
\hline $\begin{array}{l}\text { Recovered } \\
\text { energy }^{3}\end{array}$ & 0.13 & 2 & 2 & 2 & 2 & 0 & 0 & 0 & 1 & 1 \\
\hline Recyclable ${ }^{4}$ & 0.17 & 2 & 1 & 1 & 1 & 2 & 1 & 2 & 0 & 0 \\
\hline $\begin{array}{l}\text { Reduce resource } \\
\text { use }^{5}\end{array}$ & 0.20 & 2 & 2 & 2 & 1 & 1 & 0 & 0 & 0 & 0 \\
\hline $\begin{array}{l}\text { Reusable and } \\
\text { refillable }^{6}\end{array}$ & 0.05 & 2 & 2 & 1 & 1 & 0 & 0 & 2 & 0 & 0 \\
\hline $\begin{array}{l}\text { Waste } \\
\quad \text { reduction }\end{array}$ & 0.12 & 1 & 2 & 2 & 2 & 0 & 1 & 0 & 2 & 2 \\
\hline Total score ${ }^{8}$ & & 1.32 & 1.27 & 1.32 & 1.02 & 0.73 & 0.49 & 0.63 & 0.61 & 0.61 \\
\hline
\end{tabular}




\section{B.1. Scoring criteria}

In some qualitative methods, the scale maybe measured in $1-5,1-9$ or $1-10$. But in this case, we just to judge whether the materials have the properties fitting the evaluation factors or not. Thus, the materials were divided into three level: the best (completely fitting) get two points, medium (partial fitting) get one point, the inferior (absolutely not fitting) get zero point.

1. Two points for materials which can be composted completely and one point for materials which can be partly composted and zero point for materials that cannot be composted. In this item, only paper materials have this property.

2. Two points for materials that consist of single material and one point for materials consist of complex materials with easy disassembly, and zero point for materials consists of complex materials with hard disassembly.

3. Two points for materials which have higher heat values in incinerators and one point for materials which have lower heat values and zero for materials almost have no heat value. According to previous research (Taiwan EPA, 1998), the materials are divided three levels by cluster analysis on the heat value of recycling.

4. According to recycling material data from Taiwan's EPA, we give two points to materials that have the highest amount of recycled content and one point for materials that have less recycled content and zero for materials have the least. The materials are divided three levels by cluster analysis on the amount of recycling.

5. Better scores are given for processes that use less electricity. The reference resources are BUWAL250 and IDEMA database. The materials are divided three levels by cluster analysis on electricity consumption.

6. Better scores are given for processes that have more frequency of packaging containers reusing or refilling. The materials are divided into three levels by cluster analysis on reuse frequency which was obtained by questionnaire from Taiwan inhabitants.

7. Better scores are given for processes that have few average function units of packaging materials. The reference resource is Table 2 .

8. The total score of each materials, $T_{i}$, is given by:

$T_{i}=\sum_{i=1}^{9} E_{i j} W_{j}$ for $j=1,2,3, \ldots, 7$

where $E_{i j}$ is the given score $(0,1$ or 2$)$ to $i$ material associated $j$ evaluation factor, $W_{j}$ is the weight of $j$ evaluation factor by AHP questionnaire.

\section{References}

Ayalon O, Avnimelech Y, Shechter M. Application of a comparative multidimensional life cycle analysis in solid waste management policy: the case of soft drink containers. Environ Sci Policy 2000;3:135-144.

Bryman A, Burgess RG. Qualitative research. London: SAGE, 1999.

Curran MA. Environmental life-cycle assessment. New York, NY: McGraw-Hill, 1996.

European Commission. Proposal for a Directive of the European Parliament and of the Council Amending Directive 94/62/EC on Packaging and Packaging Waste, Brussels, 2001.

Finnveden G, Ekvall T. Life-cycle assessment as a decisionsupport tool - the case of recycling vs. incineration of paper. Resour Conserv Recy 1998;24:235-256.

Freire F, Thore S, Ferrao P. Life cycle activity analysis: logistics and environmental policies for bottled water in Portugal, vol. 23OR Spektrum, 2001. p. 159-182.

Goedkoop M. The Eco-indicator 95 (final report), Pre Consultants, the Netherlands, 1995.

Hair JF Jr, Anderson RE, Tatham RL, Black WC. Multivariated data analysis. 4th ed. Englewood Cliffs, New Jersey: Prentice-Hall, 1995.

Hertwich EG, Pease WS, Koshland CP. Evaluating the environmental impact of products and production processes: a comparison of six methods. Sci Total Environ 1997;196:1329.

ISO. Environmental management - life cycle assessment principles and framework, International Standard 14040, International Standards Organization (ISO), Geneva, Switzerland, 1997.

ISO. Environmental labels and declarations - self-declared environmental claims (type $\alpha$ environmental labeling), International Standard 14021, International Standards Organization (ISO), Geneva, Switzerland, 1999.

Knoepfel IH. The importance of energy in environmental life cycle assessments of packaging materials. Packag Technol Sci 1994;7:261-271. 
Kooijman JM. Environmental assessment of packaging sense and sensibility. Environ Manage 1993;17(5):575-586.

Kuta CC, Koch DG, Hildebrandt CC, Janzen DC. Improvement of products and packaging through the use of life cycle analysis. Resour Conserv Recy 1995;14:185-198.

Oki Y, Sasaki H. Social and environmental impacts of packaging (LCA and assessment of packaging functions). Packag Technol Sci 2000;13:45-53.

Satty TL. The analytic hierarchy process. New York, NY: Mcgraw-Hill, 1980.

Song HS, Hyun JC. A study on the comparison of the various waste management scenarios for PET bottles using the lifecycle assessment (LCA) methodology. Resour Conserv Recy 1999;27:267-284.

Sonneveld K. The role of life cycle assessment as a decision support tool for packaging. Packag Technol Sci 2000;13:5561.
Taiwan EPA. A evaluation of energy recovery feasibility on PS containers/cardboard boxes/Tetra Paks. EPA044880109, Taiwan EPA, Taipei, 1998 (in Chinese).

Taiwan EPA. Solid Waste Management, available from http:/ /www.epa.gov.tw/ Oct. 2002.

Van Dam YK, Van Trijp HCM. Consumer perceptions of and preferences for beverage containers. Food Quality Prefer 1994;5(4):253-261.

Van Dam YK. Environmental assessment of packaging: the consumer point of view. Environ. Manage. 1996;20(5):607614.

Worrell E, Faaij APC, Phylipsen GJM, Blok K. An approach for analyzing the potential for material efficiency improvement. Resour Conser Recy 1995;13:215-232. 